\title{
Role of Magnetic Resonance Imaging in the Diagnosis of Cervical Disc Herniation: Comparison with Peroperative Findings
}

Tarannum Morshed ${ }^{1 *}$

Shahara Haque ${ }^{2}$

Md Abdul Awwal ${ }^{3}$

Naffisa Abedin'

Sadia Sultana ${ }^{2}$

'Department of Radiology \& Imaging Bangladesh Institute for Research \&

Rehabilitation in Diabetes,

Endocrine \& Matabilic Diseases (BIRDEM)

Dhaka, Bangladesh.

${ }^{2}$ Department of Radiology \& Imaging Dhaka Medical College

Dhaka, Bangladesh.

${ }^{3}$ Department of Orthopedic Surgery Bangabandhu Sheikh Mujib University Dhaka, Bangladesh.
${ }^{*}$ Correspondence to:

\section{Dr. Tarannum Morshed}

Senior Medical Officer

Department of Radiology \& Imaging

Bangladesh Institute for Research \&

Rehabilitation in Diabetes,

Endocrine \& Matabilic Diseases (BIRDEM)

Dhaka, Bangladesh.

Mobile : +8801818464627

E-mail:awwal70@yahoo.com

\begin{abstract}
The present method comparison study was carried out in the Radiology and Imaging Department of Dhaka Medical College \& Hospital, Dhaka during the period of January 2012 to December 2013 to evaluate the role of Magnetic Resonance Imaging in the diagnosis of cervical disc herniation. A total of 40 patients having clinical features of cervical disc herniation with neck pain referred to the Department of Radiology \& Imaging for MRI of their cervical spine were included in the study. At first all the patients were evaluated by detail history and clinical examination with special emphasis on clinical features. Then subsequently MRI of cervical spine was performed in all cases. The MRI report was checked by a competent radiologist of the department of Radiology and imaging DMCH. Among these 40 patients 11 were operated in department of neurosurgery, DMCH and 29 were operated in spine surgery unit, Department of Orthopaedic, BSMMU, Dhaka. The MRI and peroperative findings of these 40 patients were analyzed for the study. MRI findings correlated well in most of the cases with preoperative findings. Sensitivity, specificity, positive predictive value, negative predictive value and accuracy of MRI in the diagnosis of cervical disc herniation were $94.12 \%, 83.33 \%, 96.97 \%, 71.43 \%$ and $92.5 \%$ respectively. Therefore it can be concluded that MRI may be used as a reliable tool with which we can assess the level, type and position of cervical disc herniation and can plan the subsequent appropriate management in majority of cases.
\end{abstract}

Key words : Magnetic Resonance Imaging (MRI); cervical disc; Radiology \& Imaging; herniation.

\section{INTRODUCTION}

Cervical intervertebral disc herniation is an important cause of neck and arm pain. Herniation of disc is defined as a localized displacement of disc material beyond the limits of the intervertebral disc space. This herniation results in neck and arm pain with paresthesias in a dermatomal distribution and muscle weakness.

Herniation may be described as a protrusion, extrusion or sequestration. In protruded type of disc herniation displaced disc material remains in continuity with the disc of origin and contained by annulus fibrosus. In extruded type disc material migrate through the annulus fibrosus but contained by posterior longitudinal ligament. In sequestered type disc material is free in spinal canal. Disc herniation may be posterolateral or central. Posterolateral herniation is more common and affects the exiting nerve root. In cervical region disc herniation predominate in lower cervical level C5-6 and C6-7 . 60-75\% herniations occur at C6-7 and 20-30\% at C5-C6 level ${ }^{2}$. Symptoms may begin as localized neck pain. This pain may be followed by referred (radicular) pain going down in the arm or forearm, this suggest progression of disease and indicate nerve root irritation or compression. Other symptoms include sensory loss, parasthesias and hyporeflexias. Disc herniation along with ligamentum flavum hypertrophy can cause acquired canal stenosis when the spinal canal diameter is less than $13 \mathrm{~mm}$ in cervical region. This results in myelopathy causing weakness and wasting of hand muscle, weakness and spasticity of the lower limbs, gait disturbances, exaggerated reflexes and $50 \%$ develop bladder symptoms ${ }^{3}$. 
Neck pain may be managed conservatively. But when absolute indications of surgery like progressive neurological deficit, bowel or bladder involvement or clinical sings due to herniation persist or progress despite of conservative management, neurosurgical opinion is warranted. The need for surgical intervention should be assessed on the basis of clinical and radiological investigations. MRI is reliable at demonstrating, soft disc protrusion in the cervical spine, where there is less epidural fat ${ }^{4}$. Thus it has become the choice of investigation for patients suspected of cervical disc herniation. The anatomy of intervertebral disc is best appreciated on T2 weighted sagittal MRI. Due to intensity differences of CSF, disc and neural tissue, excellent contrast is obtained. The axial slices demonstrate the disc bulges, protrusion, extrusion and their resultant nerve root and thecal sac compressions. Moreover with MRI an examination of the entire cervical region including the osseous structure, extradural cerebrospinal fluid interface and spinal cord can be obtained with a single modality in an outpatient setting and in a non invasive fashion ${ }^{5}$.

So the objective of this study was to determine the accuracy and to establish the validity of MRI for preoperative diagnosis of cervical disc herniation.

\section{MATERIALS \& METHODS}

The present method comparison study was carried out among 48 patients with clinical diagnosis of cervical disc herniation referred to Radiology and Imaging Department of Dhaka Medical College \& Hospital, Dhaka for MRI of cervical spine during the period of January 2012 to December 2013. The Research Protocol was approved by ethical committee of $\mathrm{DMCH}$ prior to commencement of the study.

At first all the patients were evaluated by detail history and clinical examination with special emphasis on clinical features. Subsequently MRI of cervical spine was performed in all cases. A 0.3 Tesla open MRI machine (AIRIS-II-HITACHI) was used. Images were taken at sagittal and axial sections at spin echo (SE) sequence in T1- weighted and fast spin echo (FSE) sequence in T2 weighted images using slice thickness $5 \mathrm{~mm}$, intersection gap $4 \mathrm{~mm}$.

The MRI report was checked by a competent radiologist of the department of Radiology and imaging DMCH. Out of 48 cases, 5 had only disc bulge without neurological deficit, 3 patients had refused surgery and 1 patient was unfit for surgery and peroperative findings were available in 40 patients. Among these 40 patients 11 were operated in department of neurosurgery, $\mathrm{DMCH}$ and 29 were operated in spine surgery unit, Department of Orthopaedic, BSMMU, Dhaka. The MRI and peroperative findings of these 40 patients were analyzed for the study.

Results

Highest incidents of cervical disc herniation were found in $4^{\text {th }}$ decade of life occurring in $21(52.5 \%)$ cases. Next common incidence was found in $5^{\text {th }}$ decade occurring in $14(35.0 \%)$ cases.

The sex incidence of cervical disc herniation was $28(70.0 \%)$ in male and $12(30.0 \%)$ in female. 33 patients out of 40 had disc herniation on MRI and spinal stenosis was found in 7 patients. Among 33 patients, maximum frequency $17(51.5 \%)$ of cervical disc herniation level. Next common level was $\mathrm{C}_{5-6}$ 10(30.3\%) and $6(18.2 \%)$ cases at $\mathrm{C}_{4-5}$ level. Among the 7 patients with spinal stenosis $1(14.3 \%)^{4-5}$ had relative and $6(85.7 \%)$ had absolute stenosis. Peroperative findings like level of disc herniation, type of herniation, position of disc herniation coincided with MRI findings.

In this study $32(80.0 \%)$ cases were diagnosed correctly for cervical disc herniation, 1 case of posterior longitudinal ligament ossification PLL (segmental) was diagnosed as cervical disc herniation. Again 5 cases were correctly diagnosed as spinal stanosis and 2 cases were diagnosed as spinal stenosis that had only cervical disc herniation.

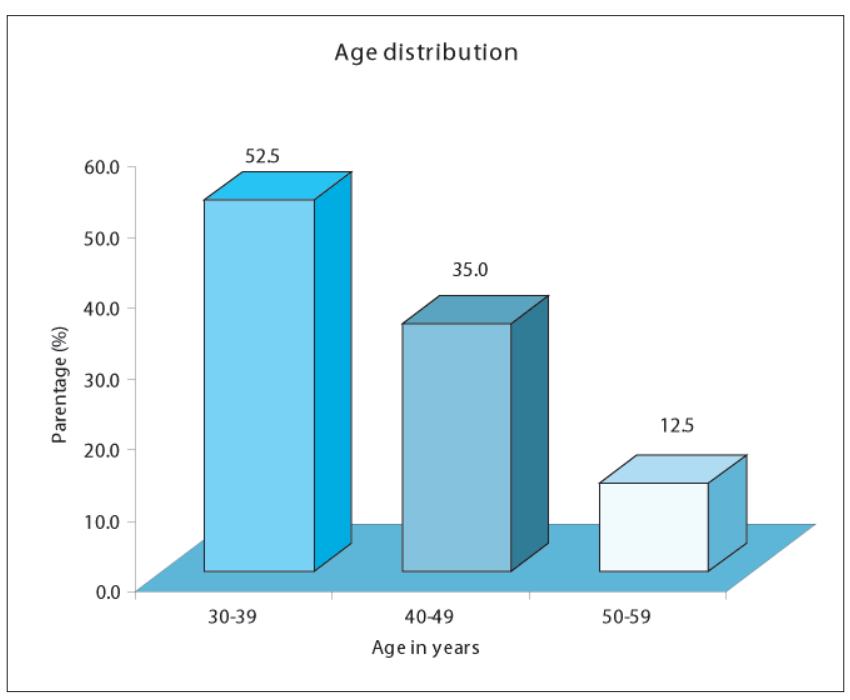

Figure 1: Bar diagram showing age distribution of the patients

Table 1: Distribution of patients according to MRI parameters

$\begin{array}{lcc}\text { MRI features of cervical disc herniation } & \text { Frequency } & \text { Parentage (\%) } \\ \text { Level of disc herniation }(\mathrm{n}=33) & 6 & 18.2 \\ \mathrm{C}_{4-5} & 10 & 30.3 \\ \mathrm{C}_{5-6} & 17 & 51.5 \\ \mathrm{C}_{6-7} & & \\ \text { Disc desiccation ( } \mathrm{n}=33) & 26 & 78.8 \\ \text { Present } & 7 & 21.2 \\ \text { Absent } & & \\ \text { Type of herniation ( } \mathrm{n}=33) & 31 & 93.9 \\ \text { Extrution } & 2 & 6.1 \\ \text { Sequestration } & & \\ \text { Position of disc herniation (n=33) } & 3 & 9.1 \\ \text { Central } & 29 & 87.9 \\ \text { Paracentral } & 1 & 3.0 \\ \text { Foraminal } & 0 & 0 \\ \text { Extraforaminal } & & \\ \text { MRI features of spinal stenosis }(\mathrm{n}=7) & 1 & 14.3 \\ \text { Relative } & 6 & 85.7 \\ \text { Absolute } & & \end{array}$

Above table shows the distribution of MRI parameters. Out of 40 patients disc herniation was present in 33 patients and spinal stenosis was found in 7 patients. Among 33 patients table shows maximum frequency $17(51.5 \%)$ of cervical disc herniation at $\mathrm{C}_{6-7}$ level. Next common level is $\mathrm{C}_{5-6} 10(30.3 \%)$ and $6(18.2 \%)$ cases at $\mathrm{C}_{4-5}$ level. Among the disc herniation 26 (78.8\%) showed desiccation. Disc extrution was found in $31(93.9 \%)$ and sequestration was present 2(6.1\%). Most of the patients 29(87.9) had paracentral disc herniation, 3(9.1\%) central and $1(3.0 \%)$ forminal disc herniation. Extraforaminal herniation was not found in any patients. Among the 7 patients with spinal stenosis $1(14.3 \%)$ had relative and $6(85.7 \%)$ had absolute stenosis. 


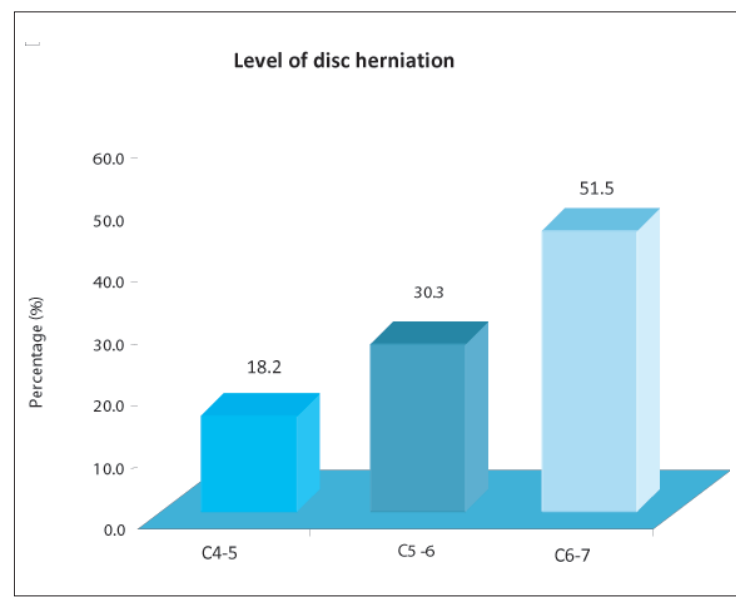

Figure 2 : Bar diagram showing level of disc herniation

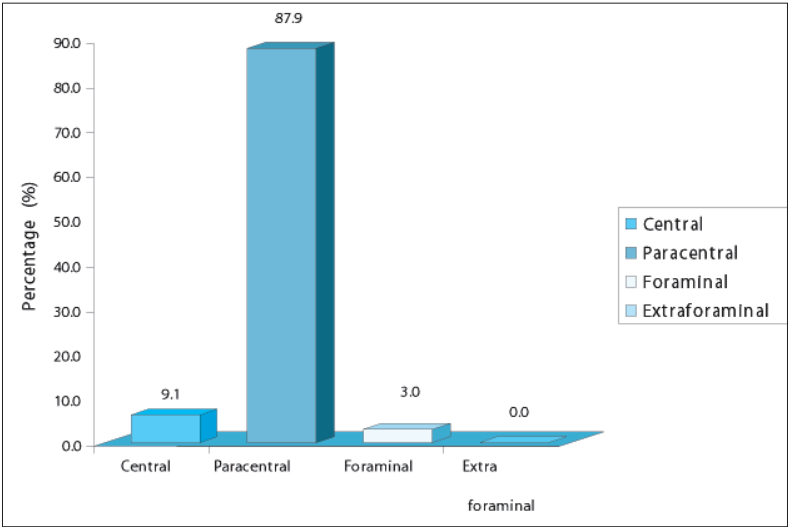

Figure 3 : Bar diagram showing position of disc herniation

Table 2 : Distribution of patients according to peroperative findings

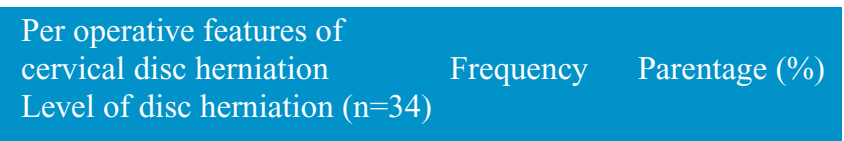

$\begin{array}{lcc}\mathrm{C}_{4-5} & 6 & 17.6 \\ \mathrm{C}_{5-6} & 11 & 32.3 \\ \mathrm{C}_{6-7} & 17 & 50.0 \\ \text { Type of herniation }(\mathrm{n}=34) & & \\ \text { Extrution } & 31 & 91.2 \\ \text { Sequestration } & 2 & 5.8 \\ \text { Position of disc herniation }(\mathrm{n}=34) & & \\ \text { Central } & 4 & 11.8 \\ \text { Paracentral } & 29 & 85.2 \\ \text { Foraminal } & 1 & 3.0 \\ \text { Extraforaminal } & 0 & 0 \\ \text { Spinal stenosis }(\mathrm{n}=6) & & \\ \text { Relative } & 1 & 14.3 \\ \text { Absolute } & 5 & 85.7\end{array}$

Above table shows the distribution of peroperative findings. Out of 40 patients disc herniation was present in 34 patients and spinal stenosis was found in 6 patients. Among 34 patients table shows maximum frequency $17(50 \%)$ of cervical disc herniation at $\mathrm{C}_{6-7}$ level. Next common level is $\mathrm{C}_{5-6} 11(32.4 \%)$ and $6(17.6 \%)$ cases at $C_{4-5}$ level. Most of the patients $29(85.2)$ had paracentral disc herniation, $4(11.8 \%)$ central and $1(3.0 \%)$ forminal disc herniation. Extraforaminal herniation was not found in any patients. Among the 5 patients with spinal stenosis $1(16.6 \%)$ had relative and $5(83.3 \%)$ had absolute stenosis.

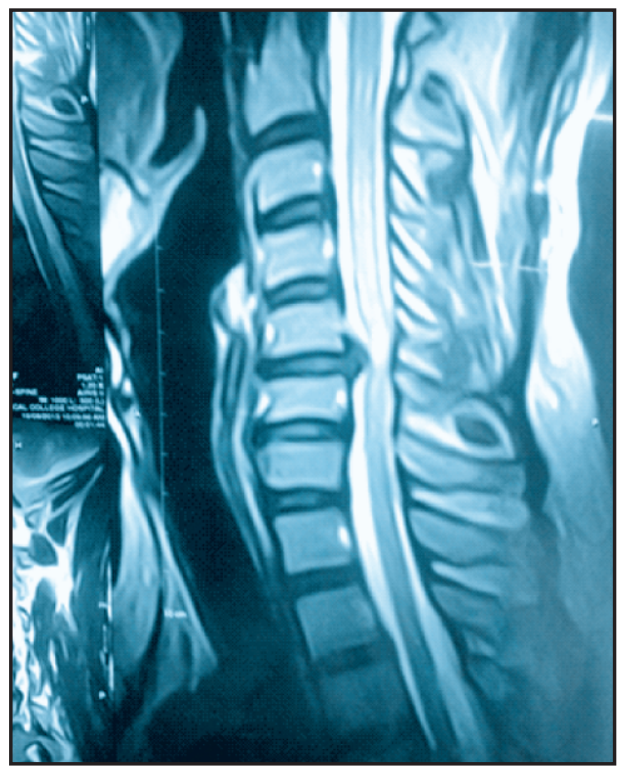

Figure 4 : MRI T2 weighted Sagittal image of extruded cervical disc at $\mathrm{C}_{5-6}$ level

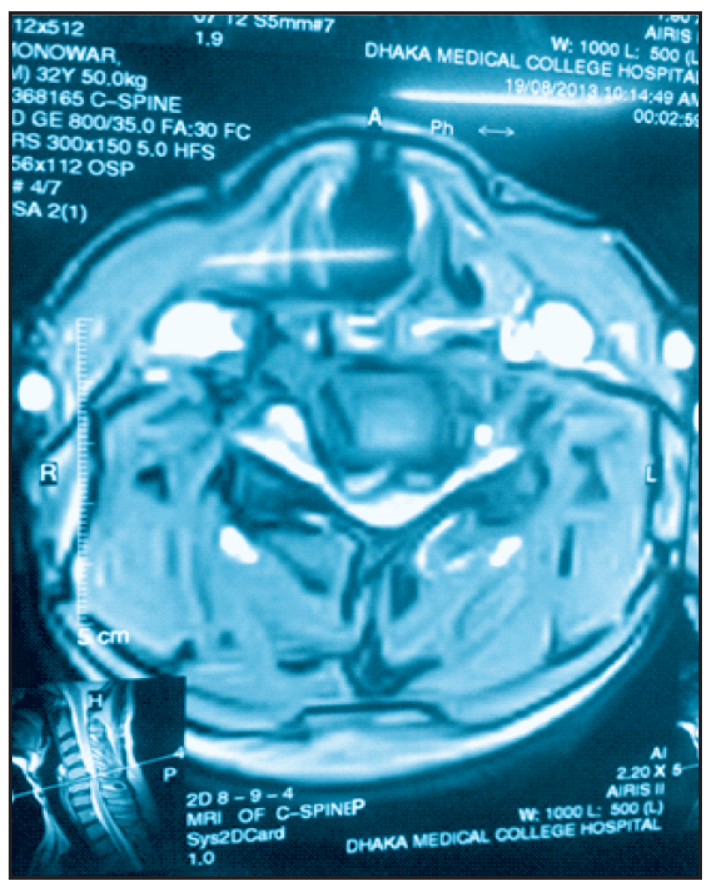

Figure 5 : T2 weighted axial image of extruded cervical disc at $\mathrm{C}_{5-6}$ level 


\section{DISCUSSION}

MRI is the primary modality for imaging the spine as it can reliably image the vertebral marrow, paravertebral soft tissue, intervertabral disc, the cord, thecal sac and the nerve roots (Ramani, 2005) ${ }^{1}$. The method comparison study was carried out to establish the usefulness of MRI in the diagnosis of cervical disc herniation with peroperative correlation. Subjects of this study were taken from Dhaka Medical College \& Hospital, Dhaka. During the study period of January 2012 to December 2013, 40 patients were included in this study as they fulfill the inclusion and exclusion criteria.

In this study $21(52.5 \%)$ cases are found between 30 to 39 years, 14 (35\%) cases cases were between 40-49years and 5 cases (12.5\%) were between 50-59 years. Peak incidence of symptomatic cervical disc herniation is between 30 years to 50 years $^{6}$.

In present study neck pain, paresthesia, sensory changes, limb weakness, abnormal deep tendon reflexes were present in most of the patients. The most common clinical findings seen in patients with cervical disc herniation is radiculopathy. The diagnosis of cervical radiculopathy can be considered in patients with arm pain, neck pain, and paresthesias, numbness and sensory changes, weakness, or abnormal deep tendon reflexes in the $\mathrm{arm}^{7}$.

Dehydrated disc due to old age is very common. Besides age, trauma or repeated injury or strain to the same area can also cause disc desiccation ${ }^{8}$. Disc desiccation was found in $26(78.8 \%)$ out of 33 patients in current study.

In this study male female ratio of cervical disc herniation was 2.3:1 (28:12). In Jeffrey's series (1986) among 127 patients with cervical disc herniation $95(72.4 \%)$ were male and $44(34.6 \%)$ were female. In an epidemiological study of acute cervical disc rupture was more common in male by a ratio of $1.4: 1^{9}$.

Men are predisposed in a ratio 3:1 and vast majority of disc lesions develop without any accidental trauma ${ }^{10}$. Our observation conformed with the findings of the above mentioned investigators.
In this study cervical disc herniation mostly seen at C6-7 level $(60 \%)$, then in C5-6 level (21.2\%) and least in C4-5 level $(18.1 \%)$. In the cervical spine the levels that are most frequently affected by disc herniation are C6-7 (60\% to $75 \%)$ and $\mathrm{C} 5-6(20 \% \text { to } 30 \%)^{11}$. In cervical region disc herniation predominate in lower cervical level C5-6 and C6- $7^{1}$. 60-75\% herniations occur at C6-7 and 20-30\% at C5-C6 level ${ }^{2}$.

In this study 7 patients were diagnosed with spinal canal stenosis on MRI which involved spinal canal, the lateral recess and neural foramina which resulted in symptoms similar to cervical disc herniation. Spinal stenosis was confirmed in 5 patients during surgery. Spinal MRI is the most suitable technique for the diagnosis of spinal stenosis. On MRI, findings of spinal stenosis have a variable presentation depending on the specific disease. The goal of spinal MRI is to localize the site and level of disease and to help differentiate between conditions in which patients require surgery or conservative treatment ${ }^{12}$. Spinal stenosis can involve the spinal canal, the lateral recess, or the neuralforamina ${ }^{13}$. In current study, MRI has $94.12 \%$ sensitivity, $83.3 \%$ specificity and $92.5 \%$ accuracy. In the study of Mogdad sensitively of MRI for cervical disc herniation was $93 \%{ }^{14}$. The accuracy of MRI for predicting presence of herniation at surgery was about $92 \%{ }^{15}$.

Our study reveals among the cases diagnosed on MRI as cervical disc herniation, $96.9 \%$ were proved to be cervical disc herniation during operation. At the operation levels, there was $100 \%$ agreement between MR and surgical findings for cervical disc herniation ${ }^{16}$.

\section{CONCLUSION}

This study showed the comparison between MRI findings of cervical disc herniation and peroperative findings. MRI may be used as a reliable tool with which we can assess the level, type and position of cervical disc herniation and can plan the subsequent appropriate management in majority of cases. MRI is safe and cost effective.

\section{DISCLOSURE}

All the authors declared no competing interest.

\section{REFERENCES}

1. Ramani P.S. Textbook of Spinal Surgery. New Delhi, Jaypee brothers $2005 ; 286$.

2. Osborn, A.G. Diagnostic Neuroradiology. St. Louis, Mosby Elsevier 1994; 850.

3. Ray, A., Cowie, R. What should be done for the patient with neck pain (when plain x-ray says spondylosis). Arthritis research campaign. 2005 Available from: www.arthritisresearchuk.org/ /media/files.On/1 P 07-jan2002.ashx.

4. Keith, D.W. \& Ashley, L.P. Lower Back Pain and Disorders of Intervertebral Discs. In: Canale, S.T. \& Beaty, J.H. editors. Cambell's Operaive Orthopeadics. Philadelphia, Mosby Elsevier, 2007;1292

5. Modic, M.T., Ross, J.S. Masaryk, T.J. Imaging of degenerative disease of cervical spine. Clin Orthop Relat res. 1989; 239:109-120.

6. Toshiki, A. Symphtomatic cervical disc herniation in teenagers: two case reports, Journal of medical care reports. 2013;7: 42.

7. Christopher, M.B. Diagnosis and Treatment of Cervical Radiculopathy from Degenerative Disorders. North American Spine Society: 2010;12.

8. Buzzle.com. disc desiccation. [online]. 2012: available from: http/www.buzzle.com/arteicals/discdesicationhotmail.

9. Kelsy, J.L., Githens, P.B., Walter, S.D. An epidemiological study of acute prolapsed cervical intervertbral disc. J Bone Joint Sur, 1984;66:907.

10. Turek, S.L. The cervical spine. In: Pederson, DD editors. Orthopaedics Principles and the application. Pennsylvania, J.B. Lippincott Company. 1989.

11. Russell, E,G. Cervical disc disease, Radiology Journal. 1990; 177: 313-325.

12. Maryam, B. MRI findings in spinal canal stenosis. Iranian Journal of Radiology, 2010; 7: 25

13. Kenneth, M.A. \& Jhon, R.H. MR Imaging of spinal senosis. Applied Radiology. 1997; 26.

14. Mogdad, F.A., Nofal, M.K., Piers M, Sean, P.H. The value of neuroplysical and imaging studies in predicting outcome in the surgical treatment of cervical rediculopathy. Eur Spine J. 2007; 16: 495-500.

15. Wilson, D.W., Pezzuli, R.T., Place, J.N. Magnetic resonance imaging in the preoperative evaluation of cervical radiculopathy. Neurosurgery.1991; 28:175-179.

16. Erik Van de Kleft, Michel Van Vyre. Diagnostic imaging algorithm for cervical soft disc herniation. Journal of Neurosurgery and Psychiatry.1994;57: 724-728. 